\title{
Wet stack - Analysis of condensation
}

\author{
Ondřej Bartoš ${ }^{1, *}$, Jan Havlik $^{1}$, and František Hrdlička ${ }^{1}$ \\ ${ }^{1}$ CTU in Prague, Department of Energy Engineering, Technická 4, Prague 6, 166 07, Czechia
}

\begin{abstract}
The aim of the paper is to introduce the study of condensation processes in the wet stack. Because of the high cost of reheating (due to the loss of useful heat of flue gases), wet stacks are being considered for new or retrofit applications of wet flue gas desulfurization (FGD) systems around the word. Wet stacks, in contrast to classical chimneys where flue gases are heated up to avoid any condensation, works with wet flue gases and condensation is welcome. The study provides a quantitative analysis of the condensation.
\end{abstract}

\section{Introduction}

At present, we distinguish between two types of industrial stacks according to the water saturation of flue gases. In the "classical" stack, the flue gas temperature is significantly above the dew point of the flue gases. This can be achieved either by exhausting the flue gases without the use of cleaning devices or by the additional heating of the flue gases after desulfurization. In both cases, no condensate under steady operating conditions will be generated in the flue gas liner, although condensation may occur in the start-up and non-design conditions.

In "wet stacks" the exhaust flue gases are saturated with moisture. A typical wet stack is located downstream of a wet Flue Gas Desulfurization (FGD) system. FGD systems reduce the sulphur dioxide $\left(\mathrm{SO}_{2}\right)$ content by spraying slurry of limestone and lime into the flue gas stream. While $\mathrm{SO}_{2}$ is scrubbed from the gas stream, water from the slurry saturates the flue gas. In addition, the relatively cool slurry typically reduces the temperature of the flue gas to the range of $45^{\circ} \mathrm{C}$ to $55^{\circ} \mathrm{C}$. Since the exhaust gas flow is saturated with water, condensation will occur in these stacks during steadystate and start-up conditions.

The construction of the typical stack has a reinforced concrete windshield with one or more flue gas liners inside. Depending on the operating conditions of the chimney and the surrounding conditions, there are three basic sources of the liquid in the flue gas liner.

We consider these resources as::

- Condensation on the liner wall due to temperature and concentration gradients

- Adiabatic condensation

- Droplets which passed through the eliminator after FGD

The condensation layer especially on the wall of the stack may be pulled back into the flue gas stream. This phenomenon may result in large drops drifting out of the chimney where they can fall on the ground nearby. The amount of falling droplets depends on the rate of combustion and the properties of the condensate layer, heat transfer and mass transfer.

Fine droplets usually evaporate before they impact the ground. However, large droplets can fall on the ground like an acid rain and cause nearby objects, equipment and vehicles to corrode. Large droplets mainly come from the condensate, which is accumulated on the wall of the liner and is pulled back from the wall and is blown out of the chimney by the flue gas. This phenomenon is sometimes called "spitting" from the upper part of the chimneys. An important aspect of the liner head arrangement is therefore to reduce the droplet size emitted from the chimney by flue gases to prevent droplets from falling to the ground.

In addition to the potential corrosion caused by the dispersion of droplets into surrounding areas, wet and acid flue gases from FGD may chemically interact with the reinforced concrete structure of its own chimney, especially on the head of the stack. Properly selected materials and well-designed condensate removal equipment can minimize the corrosion. Commonly used lining materials are acid-resistant bricks, closed-cell ceramic foam, FRP and nickel alloys. Although corrosion resistance is an important feature of the liner, thermomechanical properties such as thermal conductivity, specific heat capacity and density can also significantly affect heat transfer and mass transfer in the liner. Heat and mass transfer can then affect the amount of condensation created on the walls.

\section{Stack heat transfer}

As an example of wet stack condensation analysis the typical industrial chimney would be expected to have one liner in the construction of its reinforced concrete windshield. 
The total heat transfer through the heat transferring area is given by the equation (1).

$$
Q=U \cdot A \cdot \Delta T_{l o g},
$$

where $\mathrm{U}$ is the overall Heat transfer coefficient (HTC), A is the heat transfer surface and is the logarithmic mean temperature difference. For the case of the wet stack it is necessary to divide the heat transfer into two parts. The overall HTC for the liner is calculated from the term

$$
U_{d}=\frac{1 / D_{d-o}}{\frac{1}{d_{d-i} \cdot h_{d-i}}+\frac{1}{2 k} \ln \left(\frac{D_{d-o}}{d_{d-i}}\right)+\frac{1}{D_{d-o} \cdot h_{d-o}}},
$$

where is the inside diameter, $\mathrm{k}$ is the thermal conductivity, and is the outside diameter. The overall HTC for the concrete construction is calculated from the term

$$
\begin{aligned}
& U_{s t} \\
& =\frac{1 / D_{s t-o}}{\frac{1}{d_{t s-i} \cdot h_{s t-i}}+\frac{1}{2 k} \ln \left(\frac{D_{s t-o}}{d_{s t-i}}\right)+\frac{1}{D_{s t-o} \cdot h_{s t-o}}},
\end{aligned}
$$

The heat transfer through the liner is equal to the heat transferred through the stack

$$
Q_{d}=Q_{s t}
$$

The HTCs are determined on the basis of EN 13084-1 [1], except for the HTC on the inner side of the duct where the water vapor condenses. For the through-air gap between the duct and the stack, the HTC on the outer side of the duct is $8 \mathrm{Wm}^{-2} \mathrm{~K}^{-1}$, the HTC on the inner side of the stack is $8 \mathrm{Wm}^{-2} \mathrm{~K}^{-1}$ and the HTC on the outer side of the stack is $24 \mathrm{Wm}^{-2} \mathrm{~K}^{-1}$ Since the condensation of water vapor in a mixture with flue gases is a more complex process compared to the condensation of pure water vapor, this issue is dealt with in a separate part 2.1. The physical properties of flue gas mixture are calculated according to the composition of the specified flue gases with a consideration of the temperature.

\subsection{Condensation of water vapour in mixture with flue gas in a flue gas liner}

Condensation of water vapor in the mixture of flue gas is different from condensation of pure water vapor. In a mixture, the molecules of steam diffuse through flue gas towards the vapor-liquid interface. There is a difference in the concentrations of steam in the bulk gas mixture $C_{\infty}$ and at the condensation phase interface $C_{i}$ and mass transfer occurs [2], [3]. Steam concentrations decrease along the length of the tube at the same rate as corresponding steam partial pressures $p_{\infty}$ resp. $p_{i}$ and temperatures $T_{\infty}$ resp. $T_{i}$ (see Figure 1). On the contrary in the case of pure steam condensation, the temperatures
$T_{\infty}$ and $T_{i}$ are identical and constant during the process.

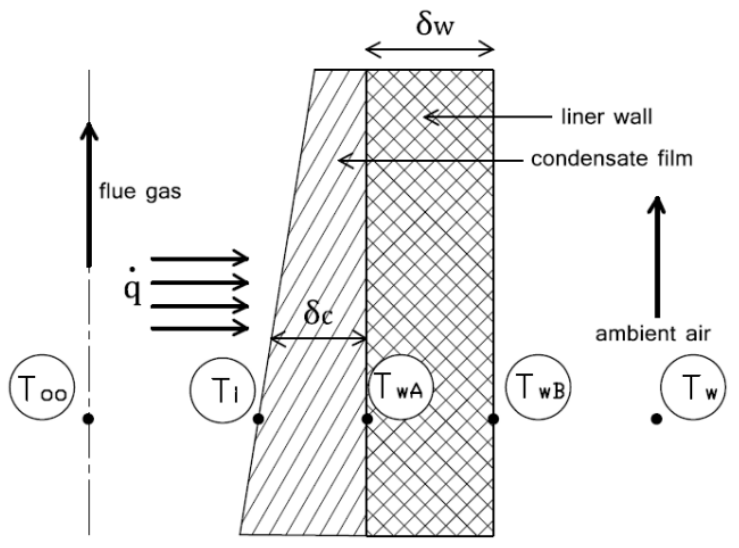

Fig. 1. Heat transfer in a flue gas liner

The water vapor concentration in the mixture decreases during the process due to water vapor condensation. In the case of a wet stack the decrease of concentration is very small; hence the dew point temperature decreases very slowly. Conversely, the concentration of flue gas, the absolute amount of which will not change, will increase. This also reduces the condensation temperature of the water vapor. The effect of the presence of noncondensing gas is twofold, apart from reducing the heat transfer rate, it is also decreases the condensing temperature during the process.

\subsection{Heat balance calculation}

The basis of the calculation model is the heat balance of the process. The heat flux from water vapor condensation is transferred through the condensate by conduction, thought the wall by conduction and between the wall and the ambient air. For the calculation it is necessary to know the temperatures of both media, the ambient air $\mathrm{T}_{\mathrm{a}}$ and the flue gas $\mathrm{T}_{\infty}$. The other temperatures between these temperature (condensation temperature $\mathrm{Ti}$ and temperature on both pipe surfaces $\mathrm{T}_{\mathrm{s}}$ and $\mathrm{T}_{\mathrm{s} 0}$ ) are determined by the equality of the heat flux.

In the total heat transfer process, the value of the heat flux $\dot{q}$ consists of the following processes:

- heat flux from the condensing steam

$$
\dot{q}=\dot{m}_{c} \cdot h_{f g}^{\prime},
$$

where $\dot{m}_{c}\left[\mathrm{~kg} / \mathrm{sm}^{2}\right]$ is the amount of condensing steam, and $h_{f g}^{\prime}$ is the latent heat of condensation.

- heat flux through condensate film

$$
\dot{q}=h_{c i} \cdot\left(T_{i}-T_{w A}\right),
$$

where $h_{c i}$ is the condensation HTC, where $T_{i}$ is the steam condensation temperature and $T_{w A}$ is the wall temperature.

- heat flux through the tube wall

$$
\dot{q}=\frac{k_{w}}{\delta_{w}} \cdot\left(T_{w A}-T_{w B}\right),
$$


where $k_{w}$ is the thermal conductivity of the wall, $\delta_{w}$ is the thickness of the wall, $T_{w B}$ is the wall temperature.

- heat flux to the ambient air

$\dot{q}=h_{w} \cdot\left(T_{w B}-T_{a}\right)$,

where $T_{a}$ is the ambient air temperature.

To determine the HTC value $T_{i}$, it is necessary to calculate the condensation temperature at the phase interface $T_{i}$ taking into account the mass transfer generated by the different partial pressures at the interface between the gas and the liquid phases $p_{i}$ and bulk gas mixture $p_{\infty}$ [1], [3], [4]. In accordance with the analogy between the mass transfer and the heat transfer, the condensation HTC is evaluated according to the Nusselt model combined with the application of the suitable criterion equation for the mass transfer.

Condensing molar flux $\dot{n}_{v}$ describes the balance of the process

$$
\dot{n}_{v}=\beta C_{T} \ln \left[\frac{1-\bar{y}_{v, \infty}}{1-\bar{y}_{v, i}}\right]
$$

where $\beta$ is the mass transfer coefficient, $C_{T}$ is the total molar concentration, $\bar{y}_{v, \infty}$ is the steam mole fraction in the bulk gas mixture, respective at the liquid-vapor interface $\bar{y}_{v, i}$. The mass transfer coefficient $\beta$ is determined according to a suitable criterial equation analogically with the heat transfer. The partial pressure $p_{v, i}$ at the liquid-vapor interface is given as

$$
p_{v, i}=\bar{y}_{v, i} p
$$

and the temperature at the liquid-vapor interface $T_{i}$ as

$$
T_{i}=T_{\text {sat }}\left(p_{v, i}\right)
$$

The HTC on the inner side of the duct $h_{d-i}$ is given after calculating the heat balance as

$$
h_{d-i}=\frac{\dot{q}}{\left(T_{\infty}-T_{w A}\right)}
$$

\subsection{Results}

A common geometry of stacks used for steam power plants was chosen for the calculation.

Stack geometry:

Stack height $\quad 250 \mathrm{~m}$

Stack inner diameter $21.771 \mathrm{~m}$ to $15 \mathrm{~m}$ in level of 194 $\mathrm{m}$ and up constant

Stack outer diameter $23.271 \mathrm{~m}$ to $15,4 \mathrm{~m}$ in level of $194 \mathrm{~m}$ and up constant

Liner inner diameter $5.3 \mathrm{~m}$

Fireclay thickness $\quad 0.1 \mathrm{~m}$

Foam glass thickness $0.05 \mathrm{~m}$

Calculation parameters were chosen in respect to the operating and climate conditions in the Czech Republic. Operating conditions:

Flue gas temperature $50^{\circ} \mathrm{C}$
Ambient air temperature $\quad-10{ }^{\circ} \mathrm{C},+10{ }^{\circ} \mathrm{C}$; resp. +30 ${ }^{\circ} \mathrm{C}$

Flue gas volume

$250 \mathrm{Nm}^{3} / \mathrm{s}$ resp. $166.7 \mathrm{Nm}^{3} / \mathrm{s}$ a $83.3 \mathrm{Nm}^{3} / \mathrm{s}$

The state with a flow rate of $250 \mathrm{Nm}^{3} \mathrm{~s}^{-1}$ and an ambient temperature of $10{ }^{\circ} \mathrm{C}$ is calculated as the basic option. Subsequently, the results were calculated for other modes of operation, taking into account changes in the ambient air temperature, in the flow rate of the flue gases and the stack construction with and without foam glass insulation.

\subsubsection{The case with foam glass insulation}

The results for the case using foam glass insulation with changes in the ambient air temperature, respective to the flue gas volume, are shown in Tab. 1 and Tab. 2.

Tab. 1 Effect of changing the ambient air temperature

\begin{tabular}{|l|l|l|l|l|}
\hline Ambient air temperature & ${ }^{\circ} \mathrm{C}$ & -10 & 10 & 30 \\
\hline Flue gas volume & $\mathrm{Nm} 3 / \mathrm{s}$ & 250 & 250 & 250 \\
\hline Transferred heat & $\mathrm{kW}$ & 175 & 117 & 58 \\
\hline Amount of condensate & $\mathrm{kg} / \mathrm{h}$ & 279 & 186 & 93 \\
\hline
\end{tabular}

Tab. 2 Effect of changing the flue gas volume flow

\begin{tabular}{|l|l|l|l|l|}
\hline Ambient air temperature & ${ }^{\circ} \mathrm{C}$ & 10 & 10 & 10 \\
\hline Flue gas volume & $\mathrm{Nm} 3 / \mathrm{s}$ & 250 & 166,7 & 83,3 \\
\hline Transferred heat & $\mathrm{kW}$ & 117 & 116 & 116 \\
\hline Amount of condensate & $\mathrm{kg} / \mathrm{h}$ & 186 & 186 & 185 \\
\hline
\end{tabular}

\subsubsection{The case without foam glass insulation}

The results for the case without foam gas insulation with changes in the ambient air temperature, respective to the flue gas volume, are shown in Tab. 3 and Tab. 4.

Tab. 3 Effect of changing the ambient air temperature

\begin{tabular}{|l|l|l|l|l|}
\hline Ambient air temperature & ${ }^{\circ} \mathrm{C}$ & -10 & 10 & 30 \\
\hline Flue gas volume & $\mathrm{Nm} 3 / \mathrm{s}$ & 250 & 250 & 250 \\
\hline Transferred heat & $\mathrm{kW}$ & 621 & 414 & 207 \\
\hline Amount of condensate & $\mathrm{kg} / \mathrm{h}$ & 991 & 661 & 330 \\
\hline
\end{tabular}

Tab. 4 Effect of changing the flue gas flow

\begin{tabular}{|l|l|l|l|l|}
\hline Ambient air temperature & ${ }^{\circ} \mathrm{C}$ & 10 & 10 & 10 \\
\hline Flue gas volume & $\mathrm{Nm} 3 / \mathrm{s}$ & 250 & 166.7 & 88.9 \\
\hline Transferred heat & $\mathrm{kW}$ & 414 & 412 & 408 \\
\hline Amount of condensate & $\mathrm{kg} / \mathrm{h}$ & 661 & 657 & 651 \\
\hline
\end{tabular}




\section{Adiabatic condensation}

This mechanism is named after the basic thermodynamic changes in which no heat is shared, the so-called adiabatic change. The change can be described by a classical relationship

$$
p v^{\kappa}=\text { konst. }
$$

or it can be expressed from the first law of thermodynamics

$$
d q=0=d i-v d p=d u+p d v
$$

However, in the case of flue gas flow in the chimney, this change cannot be considered as an isentropic change because there are additional processes (condensation, mixing) that are associated with entropy growth. The idea of adiabatic expansion in a chimney is to be considered as an approximate description, because the heat transfer is continuously going to the environment as flue gas passes through the liner of the chimney and the chimney's own concrete shaft. On the other hand, the diameter of the liner is usually in the order of meters, and therefore we can assume that a process without heat transfer occurs in the core of the flow due to the speed of transport processes such as diffusion and turbulence.

The condensation of water vapor in the flue gas stream is mainly due to the decrease of the aerostatic pressure of the flue gas with the height of the liner. This decrease can be described by a barometric equation.

$$
p=p_{0} e^{\frac{\rho_{0} g d h}{p_{0}}}
$$

When considering the decrease of the flue gas pressure with the height of the liner and assuming that the flue flows in the chimney without the heat release to the environment, we obtain from (12) a relation (13) for determining the flue gas temperature during flow in the chimney.

$$
T_{h}=T_{0}\left(\frac{p_{h}}{p_{0}}\right)^{\frac{\kappa-1}{\kappa}}
$$

The condensation occurs due to the faster drop in water vapour pressure than the decrease in total water partial pressure drop.

The flue gas density and adiabatic exponent $\kappa$ should be determined on the basis of the actual flue gas properties. Flue gas can be considered as a mixture of different gases in which each has its own specific properties. For the purposes of determining the properties in this paper, IAWPS 97 water/steam tables were used to determine the water properties $\left(\mathrm{H}_{2} \mathrm{O}\right)$ and other gases are determined using the ideal gas model for a specific molecule according to the state equation:

$$
p v=r T
$$

Where $r$ is the specific gas constant and our case of gas mixtures according to Table 5 . has a value of $285 \mathrm{~J} / \mathrm{kgK}$ and $\kappa$ is 1.37 . This approach can be considered to be accurate enough for most engineering applications.
Tab. 5 Volumetric composition of the reference flue gases

\begin{tabular}{|c|c|}
\hline Gas & Volume ratio [\%] \\
\hline $\mathrm{H}_{2} \mathrm{O}$ & cca $10-12$ \\
\hline $\mathrm{CO}_{2}$ & cca 11,5 \\
\hline $\mathrm{O}_{2}$ & cca $7-9$ \\
\hline $\mathrm{N}_{2}$ & cca 70 \\
\hline
\end{tabular}

From the equations 12 to 14 we can obtain the theoretical maximum drop in temperature given by the pressure drop in the vent and the associated temperature drop in Figure 2.

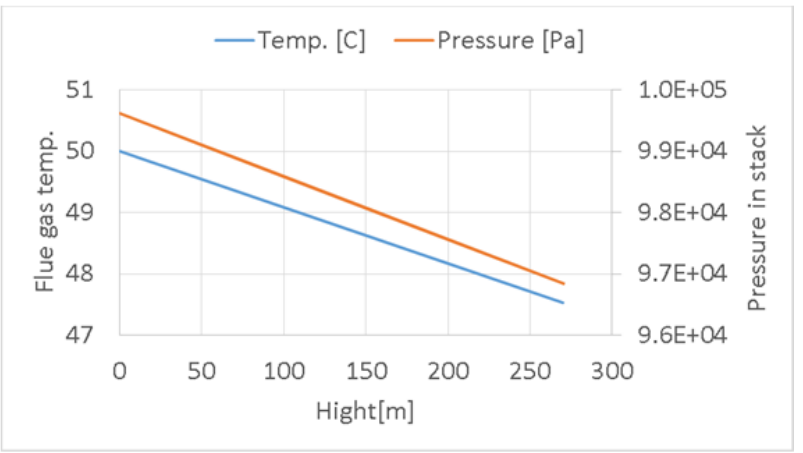

Fig. 2. Pressure and temperature profile along the stack height without condensation influence.

Figure 2. shows that the theoretical drop of the temperature is approximately $2.5{ }^{\circ} \mathrm{C}$. In this way, we could model the temperature drop in the case of unsaturated flue gas, till the saturation. In our case, we already have saturated fumes at the stack inlet. The latent heat released by the condensation is going against the temperature drop by the expansion of the flue gas in the stack.

To determine the output temperature at the liner outlet one can use a simple iteration process where the amount of heat released from the condensation will be equal to the heat required to heat the flue gas flow to the outlet temperature. The resulting output temperature drop from the iterative calculation is $0.6^{\circ} \mathrm{C}$. The actual output temperature may differ depending on the intensity of the flue gas cooling from the wall of the stack, against which various dissipative effects occur in the flue gas stream. The maximum amount of condensed liquid is about 850 $\mathrm{Kg} /$ hour in our case. This value is high, but it should be remembered that this condensation takes place in the flue gas stream. Primarily, there are already existing droplets in the flue gas stream and the surface these droplets the takes place on the surface. The transport of these droplets to the surface of the liner where they are trapped is mainly due to turbulence in the chimney. Other transport phenomena do not have a significant influence on the transfer of droplets from the main stream to the walls of the liner.

\subsection{Droplet growth}

In the following paragraph, we will focus on how much the diameter in drops present in the flue gas stream beyond the absorber will increase. The formation of new droplets resulting from homogeneous nucleation is less probable due to low supersaturation of the exhaust gas. 
The growth of drops in the flue gas environment can be written according to equation 15 .

$$
\mathrm{r}=\left(\mathrm{r}_{*}^{2}+\frac{2(\mathrm{~S}-1)}{\mathrm{C}_{1}+\mathrm{C}_{2}}\left(\mathrm{t}-\mathrm{t}_{0}\right)\right)^{0.5}
$$

Where $\mathrm{S}$ is the supersaturation and can be expressed as the ratio of the partial pressure of water vapor and the saturation pressure (16)

$$
\mathrm{S}=\frac{\mathrm{p}_{\mathrm{v}}}{\mathrm{p}_{\mathrm{s}}}
$$

$\mathrm{r}^{*}$ is the original droplet diameter at the beginning of the process. The $\mathrm{C} 1$ and $\mathrm{C} 2$ values respect the water vapor diffusivity in the carrier gas and the thermal conductivity.

To solve this project, there is no assigned water drop distribution function at the chimney inlet, so we calculate the droplet growth for 4 different diameters which are interesting for the input.

Tab. 6 Dependence of the outlet diameter of the droplet on the inlet diameter.

\begin{tabular}{|c|c|c|c|c|}
\hline$D_{\text {inlet }}[\mu \mathrm{m}]$ & 5 & 50 & 150 & 300 \\
\hline$D_{\text {outlet }}[\mu \mathrm{m}]$ & 42 & 65 & 156 & 303 \\
\hline
\end{tabular}

Table 6 shows that smaller droplets are growing faster. For larger droplets, growth is very slow, although the transport of matter is essentially the same. The driving force of condensation here is the overflow, which moves in very small quantities, so condensation cannot be expected to involve other condensing particles apart from the existing droplets. There may be such a situation when the input number of condensation seeds will not be able to satisfy the condensation flow of $\mathrm{H}_{2} \mathrm{O}$ molecules to the droplet surface, and thus the flue gas in the nonequilibrium state will leave the chimney. This would again mean a smaller amount of condensed moisture. However, this problem is very complex and requires a detailed study for each stuck situation, including the acquisition of experimental data that would determine the dimensional structure of the liquid phase at the chimney inlet as well as its output.

\subsection{Deposition of droplets on the wall}

When flue gas flows through the chimney, we assume a turbulent flow. The deposition of droplets on the wall of the liner in this type of flow is difficult to accurately model. In the literature [16], the particle concentration is assumed to be constant with respect to the cross section of the channel, and the wall is the boundary layer area where a linear decrease in concentration is considered. However, determining the thickness of the boundary layer is difficult, so semi-empirical solutions are commonly used. The main capture dominates two main mechanisms - turbulent diffusion and inertial capture. In the case of chimney breaks, we use an empirical relationship that respects both of these mechanisms.

$$
P=\exp \left(\frac{-4 V_{d e p} L}{d_{t} U}\right)
$$

Where $\mathrm{V}_{\text {dep }}$ is the deposition velocity, which could be written as

$$
V_{\text {dep }}=\frac{0,04 U}{R e^{0,25}}\left(\frac{\rho_{g} D}{\mu}\right)^{2 / 3}
$$

$\mathrm{L}$ is the length of the vent, $\mathrm{U}$ is the flue gas velocity, $\mathrm{D}$ the diffusion coefficient, Re the Reynolds flow rate and $\mathrm{dt}$ is the diameter of the liner.

The results are shown in Table 7 below

Tab. 7 Results of the deposition model

\begin{tabular}{|c|c|c|c|c|}
\hline $\begin{array}{c}D_{\text {droplet }} \\
{[\mathrm{m}]}\end{array}$ & $5 \times 10^{-6}$ & $5 \times 10^{-5}$ & $1 \times 10^{-4}$ & $3 \times 10^{-4}$ \\
\hline $\mathrm{D}\left[\mathrm{m}^{2} / \mathrm{s}\right]$ & $5 \times 10^{-12}$ & $5 \times 10^{-13}$ & $2 \times 10^{-13}$ & $8 \times 10^{-14}$ \\
\hline $\mathrm{V}_{\text {dep }}[\mathrm{m} / \mathrm{s}]$ & $5 \times 10^{-7}$ & $1 \times 10^{-7}$ & $6 \times 10^{-8}$ & $3 \times 10^{-8}$ \\
\hline $\mathrm{P}[-]$ & 0.99 & 0.99 & 0.99 & 1 \\
\hline
\end{tabular}

$\mathrm{P}$ indicates the probability of passing through the stack liner. From the values in the table, it is clear that if it were smooth without any obstructions, the capture of droplets on the wall from the mainstream would be negligible. Here, however, it is important to emphasize that obstacles in cross-section can increase the amount of drops caught, especially for larger droplet diameters. On the other hand, these obstacles need to be riddled with sharp edges from which the condensate could be pulled back into the flue gas stream.

\section{Discussion}

The analysis of the liquid formation in the wet stack provides the result that the liquid is coming mostly from the heat transfer to the environment. The amount of the condensate in the presented case is in the range of 500600 kilograms of condensate. The liquid from the adiabatic condensation is generally at the same order of magnitude as in the case of the heat transfer but most of the condensate moisture remains in the flue gas flow and is spread to the environment. For the designers of the wet stack the presented paper can be used as a guide to determine the condensate collecting system from the stack. The condensate could be usually returned to the FGD.

Together with the study of the condensation in the wet stack. The possibility $[5,6]$ of reducing the pollutants collected in the condensate liquid is clear. It is known that the condensate contains a higher concentration of pollutants in comparison with the bulk flue gases. Due to the lower temperature of the flue gas, the wet stack has slightly worse dispersion characteristic in the vicinity of the stack. The use of the wet stack can provide positive effects on the efficiency of the cycle and reduction of pollutants which are captured in the condensation process. At the moment the pollutants are measured before they enter the stack and the operators of energy facilities are not motivated to reduce the amount in the wet stack. The wider use of the wet stack with respect to lower outlet velocities and the temperature of the flue gases can provide additional decreases of pollutants. 
Acknowledgements: We gratefully acknowledge the support by the employees of Omega - Teplotechna, a.s. who provided their experience from the real-life use of wet stacks.

\section{References}

1. G. F. Hewitt, G. L. Shires, T. R. Bott, Process Heat Transfer (Begell House, New York, 2000).

2. J. Sestak, F. Rieger, Prenos hybnosti tepla a hmoty (CTU, Prague, 2004) (in Czech)

3. ČSN EN 13084-1 Volně stojící komíny - Část 1: Všeobecné požadavky, ICS 91.060.40, Praha: ÚNMZ, záŕí 2007

4. W.C. Hinds, Aerosol technology (Second Ed.). Wiley, New York, 1999.

5. de Kreij, A.; Anderson, D.K.; Increasing power plant efficiency for safe wet stack operation, Cicind report, Vol. 32, No. 1

6. B. Jezek at al,: Industrial Chimneys vs Cooling Towers: International Symposium on Industrial Chimneys and Cooling Towers, Prague, Oct 8-11, 2014 